UNIVERSUM • Vol. $30 \bullet$ No $1 \bullet 2015 \bullet$ Universidad de Talca

Las casas de la empresa: Paternalismo industrial y construcción de espacio urbano en Chile. Lota, 1900-1950

Milton Godoy

Pp. 115 a 136

\title{
LAS CASAS DE LA EMPRESA: PATERNALISMO INDUSTRIAL Y CONSTRUCCIÓN DE ESPACIO URBANO EN CHILE. LOTA, 1900-1950 ${ }^{1}$
}

\author{
The houses of the company: Industrial paternalism and urban space \\ Construction in Chile. Lota, 1900-1950
}

Milton Godoy*

\section{RESUMEN}

El artículo estudia la relación existente entre el paternalismo industrial carbonífero y la construcción de espacio urbano en Lota. Se busca aportar a la identificación de prácticas paternalistas con relación al obrero y la cooptación en que se tradujo la entrega de una habitación en un espacio urbano bajo control empresarial. Para este objetivo se analizan los mecanismos que buscaban controlar la vida de los obreros y que operaron como expresiones del paternalismo burocrático, con un carácter abarcante, intentando controlar el tiempo de trabajo y la vida extralaboral de los trabajadores carboníferos de Lota.

Palabras clave: Paternalismo, industria del carbón, Lota.

\footnotetext{
${ }^{1}$ Este trabajo forma parte del proyecto Fondecyt Regular No 1120449: "La minería carbonífera en Chile. Las estrategias empresariales de bienestar y control social. 1920-1952".

* Instituto de Estudios Internacionales (INTE), Universidad Arturo Prat. Iquique, Chile / Universidad Academia de Humanismo Cristiano. Santiago, Chile. Correos electrónicos: milgodoy@ uchile.cl; mgodoyorellana@academia.cl
}

Artículo recibido el 4 de noviembre de 2013. Aceptado el 29 de julio de 2014. 


\begin{abstract}
This paper studies the relationship between paternalism coal industry and construction of urban space in Lota. It seeks to contribute to the identification of paternalistic practices in relation to the worker and the co-option which resulted in the delivery of a room in an urban space under corporate control. For this purpose we analyze the mechanisms that sought to control the lives of the workers and that operated as expressions of bureaucratic paternalism, embracing a character, trying to control the working time and their life outside of the Lota coal workers.
\end{abstract}

Keywords: Paternalism, coal industry, Lota.

$$
\begin{array}{r}
\text { “Oh qué maravilla! } \\
\text { ¡Cuántas criaturas bellas hay aquí! } \\
\text { ¡Cuán bella es la humanidad! } \\
\text { ¡Oh mundo feliz, } \\
\text { en el que vive gente así!” }
\end{array}
$$

William Shakespeare, La Tempestad, 1611.

"No hay casa que no esté tan aseada que bien se podría comer en el suelo. En los balcones, las macetas floridas ponen su nota alegre y simpática. En las ventanas visillos blancos atenúan la fuerte claridad solar.

Me asomo no a una sino a decenas de casas. En todas hay aseo escrupuloso, muebles sencillos y bien ordenados, sobre las sillas o sobre las mesitas pańos tejidos a crochet de una blancura deliciosa. En las paredes oleográficas que representan asuntos pastoriles, o escenas de amor, retratos de familia, el chico que hizo al primera comunión o el retrato que se tomó el día del matrimonio”.

Enrique Rocca. El Sur, Concepción, 5 de octubre de 1924.

\title{
INTRODUCCIÓN
}

En 1883, el viajero Francisco Marcial Aracena escribió acerca de los estragos que provocó -años antes- la inundación de las minas de carbón de Puchoco, en la ribera norte de la península en que se ubica Lota, fenómeno que trajo consigo un alto y negativo impacto en los poblados cercanos y, especialmente, para Coronel. En esta localidad, Aracena fue testigo de sus calles desiertas y despobladas "como las avenidas de los grandes cementerios", con el 90\% de sus casas "herméticamente cerradas a semejanza de una población maldita" (Aracena, 2013:239). Una situación que le llevó a comparar la región con Andacollo y Ovalle, región minera del Norte de Chile, que recibía los reveses de la baja en la producción cuprífera. 
El citado testigo no hacía más que constatar un hecho asentado desde illo témpore: que explotaciones mineras y poblamiento han sido un binomio indisociable. En efecto, donde se descubría un mineral, aunque fuese en las más adversas geografías para el hábitat humano, llegaban trabajadores -voluntariamente o enganchados- movidos por la oferta laboral que demandaba la explotación de las riquezas minerales, haciendo emerger en antiguos despoblados existencias urbanas y citadinas ligadas inexorablemente a los vaivenes de la producción, entre los que se generaron los más precarios rancheríos, tales como el espontáneo y primigenio urbanismo de las placillas dieciochescas ${ }^{2}$, hasta los más complejos asentamientos decimonónicos finiseculares y las instalaciones del siglo XX, en que compañías de mayor envergadura explotaban yacimientos principales, modelando un particular entorno urbano. Estos mismos escenarios, que concentraron miles de trabajadores y sus familias, fueron despoblados mayoritariamente con la misma prontitud que inicialmente se ocuparon, quedando solo las mínimas huellas de sus construcciones como testigos de los otrora importantes centros urbanos. Así quedó en la memoria Carrizal, Chañarcillo, Tres Puntas y Cachinal de la Sierra, poblados que aglutinaron más de tres mil habitantes en sus mejores momentos de producción minera.

En este contexto de creación de poblados mineros, fue pionero el empresariado extranjero que invirtió en la minería del salitre y el cobre, proyectando la creación de centros urbanos asociados a las explotaciones como una manera de fijar y controlar la mano de obra en asentamientos humanos que eran propiedad exclusiva de la empresa, la que inclusive aportaba, inicialmente, los servicios públicos (posta, escuela, policía), haciéndose presente más tarde el Estado, mediante sus agencias al interior de estos poblados, constituyendo un sistema organizado de distribución espacial que en conjunto emulaba una pequeña ciudad, respondiendo a modelos tales como el Industrial Village inglés, la Cité Ouvriere en Francia, el Arbeiten Siedlungen (asentamiento de trabajo) en Alemania, la Colonia Industrial en España o los Company Town de Estados Unidos, que contaban con un proyecto arquitectónico que operaba como un referente de diseño urbano global (Garcés, 2003: 17).

En Chile, los casos más representativos tienen como escenario las tierras del salitre, donde en los denominados cantones o distritos salitreros se articuló un complejo escenario en que en el contexto de "un ordenamiento territorial espontáneo" se combinó un grupo de oficinas, un pueblo de servicios y un puerto de embarque (González y Artaza, 2013: 236 y 329). En estos cantones se erigió

\footnotetext{
${ }^{2}$ Para el estudio acabado de una placilla ver Rolando Mellafe y René Salinas. Sociedad y población rural en la formación de Chile actual. La Ligua, 1700-1850. Santiago de Chile: Editorial Universidad de Chile, 1988. También Milton Godoy Orellana. "Minería y Sociabilidad Popular en la Placilla de Ligua, 1740-1800”, VALLES. Revista de Estudios Regionales 4 (1988): 77-94.
} 
un conjunto integrado de centros habitacionales complejos -que incluían plazas, teatros y servicios tales como restoranes y hoteles- donde obreros y empleados compartían un espacio con trazados urbanos jerarquizados.

Un ejemplo más sofisticado de diseño urbano proyectado para una población ligada a su centro laboral lo constituyó la construcción en las primeras décadas del siglo XX, del poblado minero de El Salvador, propiedad de la empresa norteamericana Brading Company, que diseñó el arquitecto norteamericano Raymond Olson, con un trazado geométrico formado por anillos internos que buscaba un mejor aprovechamiento del territorio y configuró una ciudad modelo que inició sus servicios en 1959, ubicada en pleno desierto de Atacama, con anchas avenidas y calles concéntricas, en un poblado volcado hacia su interior, intentando mitigar el impacto del desierto que le bordeaba (Garcés, 2003: 131-148). Este diseño urbano cobija una ciudad totalmente jerarquizada acorde con las funciones que cada trabajador desempeńaba al interior de la empresa.

No fue el único caso. En efecto, durante el siglo XIX e inicio del XX estos ejemplos se ampliarían, siendo una experiencia pionera la suscitada en Lota, en tanto quienes aplicaron estas transformaciones fueron empresarios chilenos, primero la familia Cousiño y desde 1905 Compañía Minera e Industrial de Chile, que pasó a denominarse en 1921 Compañía Carbonífera e Industrial de Lota. Empresas que iniciaron la profundización del proceso conducente a un tipo de paternalismo orientado por las prácticas que se estaban implementando en Europa.

Este artículo tiene como objetivo analizar la relación existente entre el paternalismo industrial carbonífero y la construcción de espacio urbano en Lota en el periodo 1900-1950, un contexto temporal de alta demanda de habitaciones, en que las respuestas del Estado al problema fueron escasas y la estructuración de respuestas desde las empresas se manifestaron, principalmente, a la manera del paternalismo estudiado en el presente artículo, una realidad bastante expandida en Europa en la misma época. Cabe destacar que el análisis del fenómeno histórico del paternalismo aunque profusamente tratado en la historiografía europea ha tenido escaso eco en $\mathrm{Chile}^{3}$, donde existen importantes ejemplos a investigar, uno de los cuales es la zona carbonífera abordada en esta investigación.

Podríamos acercarnos a una definición de paternalismo industrial al considerar en este concepto un conjunto de mecanismos de control destinados a cubrir una serie de demandas sociales de los trabajadores, a saber, vivienda, salud, educación de los infantes, entretención y algunos aspectos de la sociabilidad,

\footnotetext{
${ }^{3}$ Entre los escasos ejemplos destaca el trabajo de pionero de J. Douglas Porteous (1974: 409417); y el trabajo más recientes de Hernán Venegas. "Paternalismo industrial y control social. Las experiencias disciplinadoras en la minería del carbón en Chile. Lota y Coronel, primera mitad del siglo XIX”, 2014.
} 
utilizados por las empresas para adaptar a sus operarios a las demandas al interior de las villas o poblados diseñados para su permanencia en las cercanías de las labores fabriles o extractivas, asegurando de esta forma la existencia de mano de obra segura y altamente adiestrada.

Las preguntas centrales que guían este trabajo son ¿¿de qué manera se relacionó el paternalismo industrial con la sociabilidad minera? ¿Cómo se manifestaron los intentos de control de esta sociabilidad con la construcción del espacio urbano del poblado? ¿Es posible verificar en el proceso de expansión urbana esta conjugación entre paternalismo y espacio? Así, se pretende -a la luz de la interrelación de los conceptos anteriores- contribuir a elucidar algunas de las prácticas paternalistas con relación al obrero y su hogar aplicadas en la industria del carbón de Lota durante el periodo estudiado, las que en conjunto buscaban controlar las expresiones más negativas de sociabilidad obrera que minaban -a ojos de la empresa- el normal desarrollo de la vida laboral, a saber, consumo de alcohol, juegos y espacios citadinos de juerga, que incidían en la asistencia al trabajo y, por tanto, en la productividad.

Es importante destacar que cuando se habla de paternalismo existe un componente peyorativo, que fue impuesto en Europa desde fines del siglo XIX. Esta definición, según Gerard Noiriel, resultó de la acción de los portavoces del movimiento obrero que buscaban desacreditar las acciones de los patrones. Según este mismo autor, como contraparte, los partidarios de estas prácticas "fieles a su eminencia gris, Fréderic Le Play hablan de patronazgo" (Noiriel, 1998: 18).

\section{MIGRACIÓN LABORAL A LOTA: LA IRRUPCIÓN DE NUEVOS VECINOS}

Hacia mediados del siglo XIX Lota Alto carecía de una población formada con alguna regularidad. Como la mayoría de los poblados de ocupación espontánea, se caracterizaba por un paisaje eminentemente rural, donde solo había algunos ranchos en los alrededores de la incipiente explotación minera ${ }^{4}$. En 1852, Paulino del Barrio comparó las poblaciones de Coronel y Lota, pareciéndole la primera una población que prosperaba cada día, mientras que esta última la describió como "un pueblo mezquino ahogado en su crecimiento, por hallarse rodeado de un solo establecimiento cuyos intereses todo lo absorbe"

Los datos estadísticos muestran claramente la constante expansión de la población de Lota en el periodo comprendido entre 1875 y 1940, poblado que

\footnotetext{
${ }^{4}$ Oro Negro, Coronel, 3 de septiembre de 1949.

${ }^{5}$ del Barrio, Paulino. Noticia sobre el terreno carbonifero de Coronel $i$ Lota: i sobre los trabajos de esplotacion en él emprendidos. Santiago de Chile: Imprenta Nacional, (1857): 98. La cursiva es mía.
} 
en 1875 registraba 9.599 habitantes que aumentaron en un 33,9\% en el censo de 1885, año que la población llegó a los 12.855 , para descender en un 5,8\% en el censo de 1895 y desde allí al censo de 1907 aumentar levemente en un 3,4\%. Probablemente, en esta baja y escaso crecimiento, incidió la competencia por mano de obra que significó la demanda de trabajadores para los extensos campos salitreros. No obstante, también es posible buscar una explicación en las condiciones regionales, dado que en el mismo periodo la vecina localidad de Coronel aumentó su población de manera importante, comportándose con una curva ascendente e inversamente proporcional a la curva de Lota que tendía a decrecer, mientras que Santa Juana, eminentemente agrícola, mantuvo constante su población en todo el periodo estudiado, presentando variaciones numéricamente marginales.

Entonces, es posible preguntarse ¿Cuál fue el origen de los trabajadores que migraron a la región carbonífera? Probablemente, en una primera etapa comprendida entre 1875 y 1900, quienes se trasladaron a la explotación del carbón fueron mineros especializados del Norte Chico, región que a la sazón enfrentaba una crisis productiva del cobre que no tendría solución en el periodo y que contaba con mano de obra especializada que era reconocida como "habituada al trabajo minero" (Cariola y Sunkel, 1990: 71). En 1897, un periódico de Lota afirmaba que diariamente llegaban trabajadores de diversos pueblos del Norte Chico, debido a la paralización de los trabajos mineros "cuentan que la situación por la que atraviesa el proletariado es aflictiva desesperante" ${ }^{\text {. Probablemente, hacia }}$ el fin del siglo XIX e inicio del siguiente muchos trabajadores de las decadentes e inestables explotaciones mineras del cobre -que desde mediados de los setenta enfrentaban una dura crisis que azotaba al Norte Chico- enrumbaron hacía el sur carbonífero, fenómeno del cual se hizo eco la prensa local, puesto que como afirmaba un articulista del periódico El Lota, a fines de 1877, "un buen número de mineros del cobre llegó a tentar fortuna a los distritos de Coronel y Lota" aspecto es destacable que las minas del carbón tenían sistemas de explotación en profundidad, donde operaban barreteros, apires y un conjunto de especificidades laborales que tenían similitud con las explotaciones cupríferas. Por tanto, es posible que muchos trabajadores del Norte Chico migraran hacia estas explotaciones en Lota antes de viajar a las pampas salitreras, lo que no implica que posteriormente se desplazaran en aquella dirección.

Es poco probable que los trabajadores movilizados en este periodo al sur de Chile fueran pampinos debido a que la economía de explotación salitrera se encontraba demandando trabajadores y en un periodo de expansión (1894-1896) (Cariola y Sunkel, 1990: 83). La región salitrera operó como captadora de mano

\footnotetext{
${ }^{6}$ La prensa, Lota, 25 de julio de 1897.

${ }^{7}$ El Lota, Lota, 4 y 11 de noviembre de 1877.
} 
de obra, a excepción de cuando se provocó el inicio de su caída. Esto es observable inclusive en el periodo anterior a la crisis de 1929, aproximadamente en los dos o tres años que la preceden y, principalmente, a mediados y fines de la década de 1920 cuando se llegó a un máximo histórico de 60.000 trabajadores, para disminuir a 8.000 trabajadores durante el periodo de la Gran Depresión (Cariola y Sunkel, 1990: 83).

En tanto, en la primera mitad del siglo XX la población de Lota se mantenía en constante crecimiento, aumentando sucesivamente en todos los censos del periodo estudiado, pues desde los 12.509 habitantes de 1907 la población creció en un $42 \%$ en el censo de 1920, para volver a aumentar en un $54 \%$ en 1930 , cuando existían 27.736 habitantes. Nuevamente, en el censo de 1940, la población se expandió en un 24\%, para alcanzar en 1952 los 45.411 habitantes habiendo crecido en un 32\%, con respecto al censo anterior.

En el mismo periodo, después de mediados de la década del 20, en Lota la situación estaba difícil y, para evitar el peligro que representaban a ojos de la autoridad cientos de cesantes, se inició el envío de trabajadores del carbón al norte salitrero como una forma de solucionar el problema de cesantía y posibilitar espacios de descompresión social. Un ejemplo de lo señalado se suscitó en octubre de 1927, cuando la Inspección Regional del Trabajo recibió un telegrama de la Dirección Nacional, indicándole que era posible trasladar a 400 obreros de 18 a 42 años en el trasporte Angamos, de la Armada de Chile. Después de este traslado se esperaba que la comisión que trabajaba en el enganche embarcara más trabajadores, seleccionados entre los más de 1.000 cesantes que existían en la localidad que querían abandonar el sur, "prefiriéndose a los que hayan trabajado en las salitreras y tengan sus libretas".

El problema se acentuó cuando la crisis impactó tanto al mundo carbonífero, como al salitrero y ambos enfrentaron serios problemas, especialmente en Coronel y Lota donde se apeló a la construcción de obras públicas para generar trabajo, destinadas a subsanar el negativo impacto provocado por la gran desocupación, que según, José Garrido, Gobernador de Arauco "puede asumir todavía caracteres de especial gravedad, que no es conveniente ni siquiera disimular", principalmente porque la cesantía abarcaba a más de dos mil obreros, a los que se sumaban sus familias.

Entonces, pareciera que el movimiento desde Lota a las pampas calicheras fue siempre más importante que el proceso inverso, donde los obreros retornaban principalmente al centro del país. De hecho, de un grupo de 14.302 hombres, mujeres y niños que entre septiembre y octubre de 1930, retornaron desde las salitreras, solo 63 lo hicieron a Talcahuano y Lota, eligiendo este último destino solo

\footnotetext{
8 "Envío de obreros cesantes a las salitreras", El Sur, Concepción, 3 de octubre de 1927.

9 José Garrido, Gobernador de Arauco, al intendente. Coronel, 19 de febrero de 1932. Archivo Histórico Nacional, Intendencia de Concepción, Vol. 1976, oficio Nº 10, s/f.
} 
4 trabajadores ${ }^{10}$. Paralelamente, la minería del cobre inició su recuperación y volvió a ser una importante fuente de divisas debido a la caída del salitre, aumentando también la demanda de mano de obra que en el rubro se duplicó entre 1930 y 1943 (Hurtado, 1966: 117).

De esta manera, es posible proponer que los trabajadores carboníferos provenían principalmente desde los sectores aledaños a las explotaciones, lo que no imposibilitó que llegaran en los primeros ańos trabajadores desempleados de la minería cuprífera del Norte Chico.

\section{PATERNALISMO INDUSTRIAL Y ESPACIO URBANO: LA CIUDADELA INDUSTRIAL MODELO ${ }^{11}$}

El emplazamiento y distribución espacial de los poblados mineros fue un tema de alta preocupación por parte de los dueños de las empresas explotadoras. A priori, el observador descuidado podría establecer como condición básica la cercanía a la explotación, justificada por la disminución de los tiempos de traslado, permitiendo optimizar la ecuación hombres/horas de trabajo. No obstante, aun considerando que este fue un elemento gravitante, es dable afirmar que también se necesitaba la suficiente lejanía de los centros de poder, en un lugar aislado, como diría Muñiz Sánchez "ajeno a influencias o poderes extraños" (Muñiz, 2008: 137). De hecho, para el estudio del paternalismo en Italia Augusto Ciuffeti estableció como componente esencial las necesidades territoriales que marcaban a las empresas mineras de la península, donde se construían viviendas "junto a las minas, fábricas y afines industriales, casi siempre ubicadas en zonas rurales, particularmente aisladas" (Ciuffetti, 2004: 99).

Esta aparente paradoja de cercanía y lejanía se conjugaba en la dimensión económica y política. Pero, sería en el espacio local, donde irrumpió una nueva mirada: el urbanismo, que en tanto disciplina de la distribución espacial fue uno de los elementos privilegiados del paternalismo industrial, controlando tanto su distribución, el diseño de las habitaciones, su asignación y uso, como la estética de las construcción urbana de esta denominada "ciudadela industrial modelo". Según Philip Scranton, este paternalismo se puede comprender como una extensión de la autoridad patriarcal de la familia granjera dentro del taller, en la fábrica o molino, que se presenta como una reconstitución de la dominación del padre sobre un

10 "Movimiento de obreros embarcados a los lugares que se indican en los meses de septiembre y octubre de 1930". Iquique, noviembre de 1930. Archivo de la Intendencia de Tarapacá, Vol. 1557. ${ }^{11}$ Astorquiza, Octavio y Galleguillos, Oscar. Cien años del carbón de Lota, 1852-1952. Santiago de Chile: Editorial Compañía Carbonífera e Industrial de Lota, (1951): 210. 
conjunto de obreros niños (Scranton, 1984: 235-236). En la misma dirección se orientan las constataciones de Fernando Cuevas para analizar las intervenciones paternalistas en Barruelo de Santullán, en base a cuya investigación es posible afirmar que el fenómeno suscitado en Lota tuvo ribetes similares, en tanto se buscó contribuir a la modelación de un tipo particular de espacio urbano y de trabajador, entendidos ambos como realidades alejadas del conflicto social y bajo sujeción de los intereses productivos (Cuevas, 2006: 11).

En definitiva, la idea central de los controles, diseños y manejos de los tiempos se sintetiza en la idea planteada por José Sierra Álvarez, quien estableció la propuesta del "obrero sońado", resultante de un paternalismo que buscaba controlar trabajadores, regular la atracción y disciplinamiento de sus operarios, además de controlar los espacios y tiempos de "no trabajo" (Sierra, 1990:37). La realidad descrita, para el caso de Lota se dibuja con trazos gruesos hasta el inicio de la década de 1920, manifestándose expresiones de un tipo de paternalismo que podríamos denominar del "cara a cara", donde patrón y empleado tenían mayores cercanías realizando muchas veces él mismo las labores de filantropía que los acercaba a "sus" obreros. Etapa que en Lota correspondería al periodo de Isidora Goyenechea y su "gota de leche", institución que buscaba alimentar a los hijos de los obreros. Posteriormente, este fenómeno -como analizaré en el desarrollo del texto-comienza a profundizarse, presentándose con más nitidez desde la década del veinte un tipo de paternalismo burocrático y dirigido desde una oficina de Bienestar Social, con funcionarios de la empresa que tenían dedicación exclusiva al tema. Entonces, pareciera que allí radica la esencia del paternalismo industrial: revestir de sensibilidad social la percepción de que controlando más elementos de la vida del trabajador es posible incidir en la producción. Es precisamente en este "carácter abarcante" -en el decir de José Sierra para el caso espańol- que el paternalismo funcionaba eficientemente, en tanto modelador de los trabajadores y sus familias "abraza por todos los lados a la masa pasiva a la que intenta dar forma. En su formulación acabada y extrema, el programa paternalista adolecía de horror vacui disciplinario: cualquier fisura, cualquier hueco malograría la pieza" (Sierra, 1990: 37).

En términos específicos, el paternalismo se manifiesta con claridad en el ordenamiento territorial, claramente perceptible en Lota para el periodo estudiado. En esta localidad, la morfología del terreno determina una división espacial que marca dos sectores acorde con su altitud: Lota Alto y Lota Bajo, ubicándose el primero en una meseta, que forma parte de la Cordillera de Nahuelbuta, y se encuentra inmediata al mar, donde se construyó la "ciudadela modelo" y las instalaciones industriales, que junto a las entradas a las explotaciones carboníferas se ubican en el borde costero; mientras que Lota Bajo es un emplazamiento de antigua data, surgida como un asentamiento prehispánico que posteriormente fue modelado con la distribución espacial del damero colonial, produciendo cuadras. 
Aunque el objetivo central de este trabajo es el estudio de Lota Alto, para una mejor comprensión del fenómeno se deben comparar ambas realidades. En este sentido, es posible afirmar que Lota Bajo fue un espacio fuera del control empresarial. Pero, también es dable destacar que este espacio participaba en el universo industrial como emplazamiento urbano de mano de obra prescindible y que, a diferencia de los trabajadores insertos a intramuros de Lota Alto, no era gravitante para el funcionamiento de la empresa. Paralelamente, Lota Alto contenía la denominada "ciudadela modelo" era un recinto cerrado, controlado y jerarquizado que permitía vigilar los flujos de ingreso y salida del espacio urbano empresarial. Tanto las habitaciones de obreros, empleados y el sector de servicios, como el sector industrial de Lota estaban limitados por enrejados y murallas que impedían el paso de extraños y mercaderías no deseadas, tales como vendedores ambulantes, prostitutas, el ingreso de alcohol u otros productos prohibidos al interior.

Lota Alto no fue el resultado de un diseńo planteado ex profeso y de una vez, sino que se fue articulando en el tiempo, siendo mayor la intensidad de transformación después de la década del veinte en el siglo pasado. Las principales características del poblado se manifiestan en el emplazamiento del parque privado de catorce hectáreas y la residencia palaciega del patrón-empresario en la altura (1895-1898), circundado por el entramado urbano, que diseñado por la empresa constituía su espacio de control. En este entramado urbano se incluían los módulos y pabellones para obreros, distribuidos en forma reticulada, unidos por pasillos cubiertos que los comunicaban entre sí, sumándose las casas de los funcionarios con labores administrativas, separados en módulos para empleados, y servicios públicos, tales como la escuela, el hospital, la gota de leche, en un entramado citadino que con el paso del tiempo anexaría infraestructura deportiva y cultural.

Históricamente, la carencia de habitaciones fue un problema mayúsculo en la región -y el país- en la primera mitad del siglo XX. De hecho, el gobernador de Arauco solicitaba en 1932 a las autoridades del gobierno central la construcción de viviendas "sencillas pero higiénicas, de bajo costo, tanto en Lota como en Coronel, porque casi todas las habitaciones obreras que existen fuera de las compañías son inhabitables" ${ }^{\prime 2}$. No obstante, esta fue una realidad que se acentuó en el sur de Chile después del terremoto acontecido el 24 de enero de 1939 en Chillán, localidad distante un poco más de 100 kilómetros de Lota y que significó en esta última la destrucción y demolición de importante número de casas, especialmente en la localidad de Lota Bajo.

El mismo año del terremoto Gerardo Guzmán, a la sazón, Director General de Sanidad, elaboró un informe acerca del impacto del sismo en Lota Bajo que permite

\footnotetext{
${ }^{12}$ Oficio del Gobernador de Arauco, Coronel, 13 de julio de 1932, Archivo Histórico Nacional, Intendencia de Concepción, Vol. 1976, oficio 829, fs, 25.
} 
visibilizar la realidad del periodo al detectar que la destrucción provocada por este fenómeno telúrico, aumentó la escasez habitacional y develó no solo esta carencia, sino que un conjunto de elementos nocivos para la población de Lota Bajo que se desprendían de esta misma situación. La autoridad destacaba en su informe las malas condiciones sanitarias que se suscitaban en una población construida en Lota Bajo, en terrenos de la compañía carbonífera, en que predominaba el hacinamiento y la promiscuidad en pequeños cuartos de tres por tres metros -que servían de dormitorio, comedor y cocina- con pisos de tierra, la mayoría sin ventanas y construidas con madera y techumbre de teja, distribuidos en ocho grupos de edificación continua. Durante gran parte del día la habitación permanecía llena del humo de la cocina y en el invierno se convertían en lodazales por el agua que circulaba en su interior. Estas habitaciones cobijaban a grupos humanos formados por 5 a 15 personas, con un promedio de 10 , de los cuales el $50 \%$ eran niños que debían compartir las dos camas que cabían en el pequeńo espacio, exponiendo a los demás a dormir en el suelo.

En su visita, Gerardo Guzmán pudo comprobar que se usaba el sistema de camas "por turno" -también conocido como "cama calientita"- pues encontró obreros durmiendo en el día "en camas que se habían desocupado hacía poco, sin dar lugar a la ventilación de las ropas"13. El tema se complicaba con la total carencia de servicios sanitarios, como escribió el citado Guzmán "No hay un W.C., no hay un solo baño ni agua potable. Todo debe hacerse en el cerro y bosques vecinos, e incluso ir a buscar agua que, afortunadamente y por excepción, es buena"14. Esta situación extrema vivida por los habitantes de Lota Bajo alcanzaba también a la población pesquera, quienes además de carecer de condiciones de habitabilidad debían pagar entre $\$ 18$ y $\$ 30$ pesos por concepto de arriendo.

El resumen del Director de Sanidad fue categórico y estaba marcado por dos hechos de capital importancia: la escasez de habitaciones, que calculó en alrededor dos mil para satisfacer las necesidades de la población y la absoluta inhabitabilidad de las viviendas existentes. No obstante, el corolario más interesante de Guzmán fue considerarse limitado en su capacidad de acción para declarar en condición de insalubre esta población, puesto que reunía a alrededor de 1.000 personas y le hacía enfrentarse a un problema "de alcance social de proporciones ya que por falta de habitaciones sus pobladores se verían en la obligación de abandonar el pueblo de Lota lo que afectaria los intereses de la Compañia Carbonifera" 15.

El tema de las habitaciones obreras en Lota Bajo generó una importante discusión en la Cámara de Diputados, donde el representante de la región Dionisio

\footnotetext{
${ }^{13}$ Gerardo Guzmán, Director General de Sanidad. Santiago, 19 de diciembre de 1939. Archivo Nacional de la Administración, Ministerio de Salud. (en adelante ARNAD, MS) Vol. 277, s/f.

${ }^{14}$ ARNAD, MS. Vol. 277, fs. 2.

${ }^{15}$ ARNAD, MS. Vol. 277, fs. 3.
} 
Garrido, a raíz de una visita realizada a la localidad, presentó una airada protesta por lo que consideraba "la forma horrorosa e inhumana" en que vivían sus habitantes en "ranchos indecentes"(Garrido, 1939: 337). En una larga disquisición este diputado del Partido Demócrata describió una situación similar a la ya señalada, solicitando la demolición inmediata de "estas pocilgas que son una afrenta pública"(Garrido, 1939: 338). Garrido indicaba a la Cámara que la población fue construida por la Caja de Seguros "con el objeto de impedir la tiranía, que en realidad ejercían las compañías sobre sus obreros. Los obreros al ser despedidos no tenían donde vivir y debían irse a habitar pocilgas inmundas"(Garrido, 1939: 338), un nivel de abandono de los trabajadores que, para el diputado, hacía comprensible la expansión del comunismo.

Más allá de constituirse en una situación pasajera asociada al terremoto de 1939, el tema de la vivienda en la región carbonífera persistió durante la década siguiente como una de las zonas más complicadas de Chile ${ }^{16}$. En efecto, la precariedad habitacional se demostró en la encuesta realizada en Lota Bajo por una Comisión de Técnicos nombrada por decreto supremo y que trabajó entre septiembre y octubre de 1941, logrando una cobertura del 90,5\% de todos las habitantes de Lota Bajo. El problema de la habitación en Lota se expresó en cifras que resultaban alarmantes, pues de las 3.498 viviendas de Lota Bajo, de las cuales el $12,3 \%$ fueron consideradas higiénicas; el $42 \%$ estaba en condición de insalubre y $45,7 \%$ eran inhabitables ${ }^{17}$.

En Lota Alto, durante el mismo periodo se identificaron 2.646 casas, entre las que no se detectó habitaciones que pudiesen calificarse como inhabitables, de las cuales "menos de mil pueden ser consideradas insalubres, por estar un tanto vetustas" (Citado en Molina, 1948: 66). Así contextuadas en la realidad social y económica de la época y la región, la situación que enfrentaban los obreros que vivían al interior del establecimiento de Lota Alto, presentaba condiciones privilegiadas, especialmente si la comparación la hacemos con Lota Bajo. Esta diferencia tendió a aumentar después de la creación en 1922 del Departamento de Bienestar Compañía Carbonífera e Industrial de Lota. Así, los múltiples ámbitos que abarcaba el Departamento de Bienestar con sus oficinas principales ${ }^{18}$, tenían como fin -en palabras de su director-

\footnotetext{
${ }_{16}$ Bustamante, Elisa. "El problema de la vivienda en la población obrera de la Compañía Carbonífera de Lirquén”. Tesis para optar al grado de Asistente Social. Concepción: Universidad de Concepción, (1942): 31.

17 "Informe sobre encuesta de la habitación en Lota", Servicios de Salubridad Fusionados, Concepción, 10 de marzo de 1942. Citado en Molina, Silvestre. "Condición económico-social de los mineros en la zona carbonífera”. Memoria para al grado de Licenciado en Ciencias Jurídicas y Sociales. Santiago: Universidad de Chile, (1948): 65.

${ }_{18}$ Para una extensa definición de las funciones del Departamento de Bienestar ver El Sur, Concepción, 9 de octubre de 1923.
} 
el mejoramiento moral, material y económico del personal de empleados y obreros de la Compañía. Esta dependencia fue dirigida desde su fundación hasta 1948 por Octavio Astorquiza, militante del Partido Conservador, exdiputado e intendente de Chiloé hasta 1921. A propósito de una reunión con el director, Enrique Rocca dejó una detallada descripción de las actividades realizadas por estas dependencias:

destinado a proporcionar habitaciones, provisiones, instrucción, mejorar la vida social, la higiene y cuidar a los operarios y sus familias. En materias de habitaciones, se confieren premios a quienes tienen la casa más limpia y las ventanas más adornadas. Por lo que se refiere a las provisiones, se concede anticipos a los operarios, a fin de que puedan adquirir una cantidad superior de mercadería en el mercado donde, bajo el control de la Compañía, los artículos se venden a precio de costo. Existen 16 sociedades de socorros mutuos, un hospital modernamente instalado, donde los doctores proporcionan gratuitamente a los enfermos asistencia y medicinas. También son gratuitos el teatro y el cine, instalados en la plaza principal. La Compañía también proporciona, de sus fondos, centro de distracciones, el Estadio, canchas y funcionan kindergartens, escuelas elementales y profesionales ${ }^{19}$.

El citado periodista hizo hincapié en los resultados que esta política de bienestar tenía en los obreros y su sociabilidad, buscando introducir transformaciones resaltadas por la prensa local y que se entendía estaban orientadas a "mejorar su comodidad y, sobre todo, a hermosearlas, con el objeto de rodear al obrero de un ambiente agradable, que despierte en ellos el cariño por el hogar y por la familia" ${ }^{20}$, una política que se reforzaba con los premios establecidos para las casas más aseadas y para las que ostentaban los balcones mejor adornados, recibiendo por su conducta el regalo de una cocina, u otro utensilio para el hogar.

Al inicio de la década de los veinte en el siglo pasado, Lota contaba con alrededor de 100 pabellones de viviendas en bloque de construcción continua o entramada, con casas de 3 a 4 piezas para los obreros y de 5 o 6 para los empleados. La concesión de la casa funcionaba como componente del salario diferido, por tanto era entregada en comodato, un derecho real que implicaba el uso y goce del bien, mas no su propiedad, entendiéndose como un "préstamo de uso" 21. De esta manera, la concesión de vivienda era una prerrogativa destinada a los

\footnotetext{
${ }^{19}$ Rocca, Enrique. "El Chile que vio un periodista italiano que viajaba en la nave Italia", El Sur, Concepción, 5 de octubre de 1924.

20 "La situación del obrero carbonífero de Lota", El Sur, Concepción, 5 de abril de 1924.

${ }^{21}$ El artículo 2.174 del Código Civil chileno define el contrato de comodato como "un acuerdo de voluntades en que una de las partes entrega a la otra gratuitamente un bien, mueble o raíz, para que haga uso del mismo, con cargo de restituírselo después de terminado su uso". Código Civil de la República de Chile. Santiago de Chile: Editorial Jurídica de Chile, (2011): 221.
} 
trabajadores de buen comportamiento y cuya labor era considerada de importancia en la distribución de funciones productivas. Era en este espacio donde el obrero mixturado en aparente horizontalidad con el empleado desarrollaba su sociabilidad cotidiana al alero de la empresa que, sobremanera, se consolida con la entrega de una casa para el trabajador y su familia en un contexto social donde era más fácil encontrar trabajo que un lugar digno donde vivir.

No obstante, esta fue una realidad permanentemente cuestionada por los trabajadores que visibilizaron claramente los peligros que este control subliminalmente escondía, puesto que a la menor oposición frente a las directrices emanadas del patrónempresario el "mundo feliz" se fracturaba, debiendo ser abandonadas las viviendas al mediar su despido o el cese de las labores. Como escribió un cronista de El Alba en agosto de 1903: "Creerán los trabajadores que los huérfanos i viudas tendrán mañana un óvolo de los dueños del Establecimiento, no, tres pesos ochenta centavos mensuales si acaso el jefe lo quiere, o de lo contrario buscar hombre o marido i si no, fuera de la casa que cuando la bestia vivía [la compañía] le prestaba"22.

En síntesis, el Departamento de Bienestar de Lota impulsó la creación de instituciones que generaran una nueva sociabilidad obrera alejada de los vicios y de la participación política, destacando la creación de mutuales, clubes deportivos, academias de baile, llegando a contar con 14 instituciones de estas características, las que en conjunto agrupaban a casi tres mil personas que se beneficiaban de las políticas de incentivo de la empresa ${ }^{23}$. Sin duda, para la empresa y sus adláteres este

${ }^{22}$ El Alba de Lota, el sábado 15 de agosto de 1903. Ver también "El minero convertido en bestia", La Defensa, Coronel-Lota, 18 de septiembre de 1904; "Obra vil", La Defensa, Coronel-Lota, 28 de mayo de 1905; "Un abuso que no tiene calificativo", La Defensa, Coronel-Lota, 18 de junio de 1905; "Las antesalas de la muerte o sea las habitaciones de los mineros", La Jornada, 14 de noviembre de 1920; "El hambre amenaza a los hogares de los obreros carboníferos", El Asalariado, Concepción, 29 de noviembre de 1925; "Guerra al FEUDO LOTINO sostenido con saña por la Cía. Minera e Industrial de Chile", Independiente, Coronel, 28 de enero de 1933; "Un mayordomo evangélico procede abusivamente con los mineros. Una de las tantas arbitrariedades que comenten los empleados de la Cía. Minera e Industrial de Chile.- Tratando de evangelizar a los mineros", La Voz Obrera, Concepción, 25 de febrero de 1933; "En la zona del carbón se tiene a los obreros sometidos a los caprichos de la Compañía”, La Voz Obrera, Concepción, 18 de marzo de 1933.

${ }^{23}$ Analizar las oficinas que componían el departamento permite formarse una clara idea de la política de incentivo a los trabajadores: $1^{\circ}$. Admisión de obreros que tiene a su cargo los registros, examen médico, Tarjetas de admisión y permiso, Escalas de salario, Traslados, Calificación, Recomendaciones para aumentar la asistencia al trabajo. $2^{\circ}$. Población a quien corresponde el censo general, censo por pabellones, agua potable, desagües, alumbrado, aseo, pavimentación, visitas de revistas de habitaciones, premios a la mejor conservación, registro de calificaciones para la concesión de habitaciones, distribución de los obreros en la población según sus oficios, sus locales de trabajo, sus buenas costumbres, etc. $3^{\circ}$. Composturas de casa; reparaciones, pinturas, registro general de habitaciones indicando tipo de pabellones, baños, W.C., lavaderos, hornos, registro por pabellones indicando tipo de casas, con anotación de puertas, ventanas, escaleras, chimeneas, cocinas, lavaplatos, carboneras. $4^{\circ}$. 
era motivo de regocijo, pues se consideraba en 1923 que la sociabilidad obrera en Lota "va tomando un rápido desarrollo que, ojalá para su propio bienestar, llegue a acentuarse y a abarcarlos a todos, [...] Esto, sin contar los beneficios que obtienen de la cooperación recíproca, de las prácticas deportivas y de la obra de difusión cultural que ya se está desarrollando con resultados halagüeños"24.

\section{LA CASA FAMILIAR: UN PREMIO PARA EL OBRERO MODELO}

En la propuesta paternalista existe un fuerte componente comparativo entre empresa y familia, la recurrencia de este parangón considera que ambas instituciones contienen amplias similitudes basadas en mecanismos tales como: existencia de jerarquías, cooperación entre sus miembros, relaciones de poder en su interior y existencia de un aparato disciplinario, donde recurrentemente el jefe se asimila al padre, en tanto "igual que un padre el patrón o el jefe de personal será protector y bondadoso, pero a la vez severo" (Babiano, 1998: 23). Continuando esa línea de análisis, es posible observar que ambas instituciones -tanto la familia como la empresanecesitan de un espacio físico para su desarrollo normal. Por ende, en la configuración de estas realidades lo espacial juega un papel definitorio, haciendo necesaria como condición sine qua non su existencia. Esta necesidad de espacio fue la que marcó la relación empresa-familia, debido a que la propiedad del territorio se concentraba en la empresa, que contaba con grandes extensiones de terrenos para destinarlo a discreción de sus intereses a la producción de espacios urbanos controlados donde asentar sus dependencias administrativas, servicios y fijar la mano de obra. Como contraparte, en la realidad social y económica de la primera mitad del siglo XX, con especial énfasis en sus primeras décadas, el asunto de las habitaciones para obreros fue un tema de alto impacto en la sociedad chilena que motivó propuestas presidenciales, discusiones en el senado y los atisbos de las primeras iniciativas legislativas -tal como la Ley de Habitación Obrera de 1906- para estimular la construcción de viviendas higiénicas destinadas a los obreros (Oficina del trabajo, 1911; Hidalgo, 2005: 5355). Este tema fue de alta gravitancia en el periodo, llegando a considerarse como un elemento que garantizaría la estabilidad social en un contexto álgido en la demanda de bienestar de los sectores deprivados de la sociedad chilena de la época.

Almacenes, mercado, provisión de carbón; lista de precios, control de pesos y medidas, despacho de vales de mercaderías, despacho de bonos de carbón y reparto, vigilancia y control de los almacenes de provisiones. $5^{\circ}$. Escuelas: censo escolar, matrícula, plan de estudios, cursos extraordinarios y especiales (vocacionales), excursiones, premios. $6^{\circ}$. Hospitales, Dispensarios, Higiene: Admisión, régimen interno, estadística, desinfección, vacuna, recomendaciones preventivas en caso de epidemias. Ver "Desde Lota Alto, el Departamento de Bienestar", El Sur, Concepción, 9 de octubre de 1923.

24 "La sociabilidad obrera en Lota", El Sur, Concepción, 8 de marzo de 1923. 
El detenido y acucioso seguimiento que la compañía realizaba a sus obreros y empleados consideraba un registro personal detallado en un expediente elaborado por el Departamento de Bienestar que se denominaba "Prontuario del trabajador", instrumento administrativo que apelando al carácter punitivo del discurso judicial, contenía el contrato, las diferentes labores desempeñadas en el trabajo (apir, fogonero, empujador, huachero, jornalero, etc.) y, en el caso de existir, su esposa e hijos. Las recomendaciones se daban apelando a estas características de orden y disciplinamiento demostrado en el desarrollo de las faenas. Un ejemplo claro es el caso de un operario que en noviembre de 1940 recibía una carta de recomendación de una autoridad de la Compañía Carbonífera de Lota: "[...] es un antiguo operario de este chiflón y nunca ha tenido casa de la compañía. La asistencia es muy buena y es muy quitado de bulla"25. Sin duda, con 299 días trabajados al ańo y manteniendo esta buena conducta, representaba el tipo de obrero ideal que ameritaba el premio solicitado a la dirigencia empresarial, cuyo departamento de bienestar le concedió lo solicitado, trasladándose al pabellón en el que vivió 18 años hasta que en octubre de $1958^{26}$ su esposa, quien había enviudado solo cuatro meses antes, se vio obligada a devolver la casa a la empresa.

Entre los miles de expedientes guardados en el archivo de la compañía, es posible encontrar las anotaciones negativas hechas a los obreros. Estas, en muchas ocasiones, marcaban su destino allanando el camino para el despido, con motivos que iban desde la embriaguez del individuo o, como resultado de la delación por participar en actividades políticas ${ }^{27}$. Al respecto, entre las fichas de los obreros destacaba una que contenía una acusación hecha en contra de uno de ellos, acusándosele de ser "espía de la federación obrera, este sujeto les trae

25 "Carta a Octavio Astorquiza, Jefe del Departamento de Bienestar", Lota Alto, 26 de noviembre de 1940. Archivo Empresa Nacional del Carbón de Lota (AENACAR), Prontuario 72, s/f.

${ }^{26}$ Lota Alto, 6 de octubre de 1958. AENACAR, Prontuario 72, s/f.

${ }^{27}$ Las persecuciones a obreros por su participación en organizaciones sindicales fueron denunciadas abiertamente en la prensa de la época, para una muestra ver los siguientes artículos: "Puede ser que de este modo el espionaje tenga menos de que ocuparse", El Alba, Coronel-Lota, 15 de julio de 1904; "Cobardes venganzas", El Alba, Coronel-Lota, 14 de septiembre de 1902; "Ecos de la última huelga", El Alba, Coronel-Lota, 31 de julio de 1902; "Temores y venganzas", El Alba, Coronel-Lota, 15 de agosto de 1903; "Se allana la casa del eterno perseguido, compañero Barrientos", La Jornada, 14 de noviembre de 1920; "La mayoría de los cesantes, han quedado sin trabajo víctimas de la intriga de los conocidísimos SOPLONES". Independiente, Coronel, 28 de enero de 1933; "Dos empleados de la Sección Ferrocarril de la Cía. Carbonífera e Industrial de Lota, fueron despedidos de sus puestos por lanzar un volante donde pedían a sus compañeros de trabajo sindicalizarse", Independiente, Coronel, 28 de enero de 1933; "A los cesantes de Lota se les lleva a trabajar custodiados, por los carabineros como a grandes criminales", La Voz Obrera, Concepción, 18 de marzo de 1933; "El terror feudal en Lota. Abusos incalificables y provocaciones en las manifestaciones obreras", La Voz Obrera, Concepción, 8 de abril de 1933; "La Compañía Schwager persigue a los Maestros Primarios", El Obrero, Coronel, 7 de octubre de 1943. 
todos los datos de la compañía a los subversivos y los tiene al corriente de lo más mínimo" ${ }^{28}$. Los datos se consignaron inmediatamente en el prontuario del delatado y fue trasladado desde su labor de celador en la población a apir en el interior de la mina. Algún tiempo después fue despedido por no considerarse necesarios sus servicios, dado que se consignó en su ficha de la empresa "que aconsejaba a la gente para que no trabajara" ${ }^{29}$. Su caso, al igual que el de otros trabajadores de las más diversas latitudes estaba marcado por el fantasma de la huelga, considerado uno de los mayores peligros por los empresarios, quienes reprimieron duramente cualquier movimiento de este tipo, ya fuese en el oeste norteamericano, como en las tierras del carbón chilenas (Porteous, 1974: 410).

De esta forma, en un complejo juego de concesiones y castigos la compañía cooptaba a los trabajadores aplicándoles una férrea disciplina que se asentaba en el contrato de trabajo y se repetía en reglamentos internos que moderaban la conducta. En cualquier momento, de sobrepasar la norma, los transgresores podían seguir el camino del ya citado trabajador, manejándose -como también constató Jorge Muñiz para el poblado de Arnao en Asturias ${ }^{30}{ }^{30}$ entre la paternal tutela dadivosa y la extrema dureza.

\section{CONCLUSIÓN}

La realidad laboral, la sociabilidad y concepción del espacio urbano en la localidad de Lota estuvieron altamente determinadas por las acciones paternalistas de la empresa carbonífera que buscó de esta manera establecer un tipo de orden espacial y social que le era obsecuente a sus intereses económicos.

A partir del análisis del conjunto de medidas adoptadas por la empresa se pueden apreciar dos fases en el desarrollo del paternalismo de Lota. En primer lugar, es posible identificar un tipo de paternalismo en que primó el cara a cara, donde dado el tamaño de la Compañía Explotadora de Lota y Coronel, creada en 1905, era posible que el patrón ejerciera directamente el conjunto de acciones paternalistas hacia "sus" obreros-nińos que requerían de esos cuidados y beneficios, para rescatarlos de $-\mathrm{O}$ a lo menos atenuar- su existencia marginal, marcada por unas vivencias estragadas, construidas al alero del alcohol y otras malas prácticas sociales. En una segunda etapa el problema tiende a complejizarse, debido a un aumento de los trabajadores y a la

\footnotetext{
28 "Carta anexa a prontuario", Lota, 24 de septiembre de 1936. (AEMCL), Prontuario 18, s/f.

29 "Hoja de servicios", Lota, 21 de febrero de 1936. ENACAR, Prontuario 18, s/f.

${ }^{30}$ Muñiz, Jorge. "La construcción social del espacio en el poblado minero metalúrgico de Arnao (Asturias), 1855-1937”, Scripta Nova. Revista Electrónica de Geografía y Ciencias sociales XI (2007): 249. Disponible en: http://www.ub.es/geocrit/sn/sn-249.htm.
} 
modernización de la empresa, lo que redundó en la instalación de un sofisticado mecanismo de control social que se materializó en el llamado Departamento de Bienestar, que regulaba el más amplio espectro de la experiencia humana al interior de la empresa. Para el caso de Lota esta institución fue creada en 1922, marcando un hito en la aplicación de nuevas orientaciones en el paternalismo, que de una acción directa -como antes señalaba- devino en un paternalismo burocrático, distribuido en diferentes oficinas que regulaban cada uno de los ámbitos que le interesaban a la Compañía Minera e Industrial de Chile, que desde 1933 y hasta 1964, se denominó Compañía Carbonífera e Industrial de Lota. Fueron los dueños y administradores de estas empresas quienes embebidos de experiencias paternalistas que se desarrollaban en Europa aplicaron estos nuevos métodos de control que rearticulaban la vida personal de los obreros, su sociabilidad y los espacios urbanos y domésticos que eran diseñados para optimizar la producción y réditos que la compañía podía esperar en el ejercicio de sus funciones.

Acorde con lo discutido en este artículo, cabe preguntarse: ¿¿ Se beneficiaron los trabajadores del carbón con las prácticas paternalistas que se han analizado? Efectivamente, mediante el análisis de esta realidad es posible captar que en términos de elementos para la supervivencia, los mineros del carbón fueron privilegiados al contar con una serie de garantías inusuales en la realidad nacional del periodo. Consecuentemente, ¿cuáles fueron las ventajas que obtuvieron los trabajadores apegados al molde paternalista en Lota? En este sentido, es dable considerar que el paternalismo como estrategia de cooptación y control de la mano de obra no fue solo represivo, sino que tuvo su cariz social que significó un mejor estándar de vida para los obreros y familias que se beneficiaron con las concesiones y premios entregados a quienes se apegaron a la normativa diseñada por la empresa. De hecho, la pertenencia al entramado urbano empresarial tenía importantes ventajas, tales como una vivienda en un espacio que se consideraba un emplazamiento modelo y con cierta dignidad en el contexto de las carencias de la época, a lo que se sumaba acceso a luz, agua potable, más 500 y 1.000 kilos de carbón para obreros y empleados. A estos beneficios se concedía acceso a atención médica, escuela para sus hijos, fomento de los deportes, existencia de espectáculos "educativos", desarrollo de una sociabilidad "sana" y de todos los elementos que la empresa incluía entre las prebendas de bienestar para los obreros y sus familias que eran considerados dignos de recibir estas concesiones. Este conjunto de prerrogativas hizo que la prensa proclive a los dueños de la empresa resaltara la unicidad de la experiencia y privilegios que los funcionarios tenían, afirmando que "creemos que en todo el país no existe un conjunto de obreros mejor ubicado y en condiciones tan favorables como las del que trabaja en las faenas carboníferas" ${ }^{\prime 1}$.

${ }^{31}$ El Sur, Concepción, 5 de mayo de 1926. 
No obstante, como los personajes de la novela de Aldous Huxley, en este "mundo feliz" el soma -aquella droga de la novela citada que curaba todas las penas y necesidades de la experiencia humana- que constituía el bienestar social, era el placebo que permitía soportar los límites al libre albedrío, donde la libertad de expresión estaba enmarcada por los muros y rejas que señalaban los límites de las casas de la compañía minera de Lota. Quienes se opusieron, -con actitudes y opciones políticas que confrontaran la disciplina interna- mediante el paro o la huelga, o no cumplieron debían abandonar esa sociedad de bienestar, haciendo del miedo al despido un aliciente para responder a las demandas de la empresa, configurando una simple ecuación donde la pérdida del trabajo significaba acabar con las condiciones asistenciales que esta entregaba, una realidad expresada con nitidez en una explicación de Octavio Astorquiza -Director del Departamento de Bienestar por 16 años- a un periodista italiano: "Ya saben ellos lo que significa un paro o la huelga. Días sin trabajo, días de miseria. Las ropitas entregadas a la voracidad del agenciero para sostener el movimiento, la expectativa de tener que abandonar la casita cómoda y errar de mineral en mineral buscando trabajo, repudiado siempre. Días sin pan"32.

El corolario de esta historia es que en una realidad política de intolerancia hacia los movimientos sociales populares y en un contexto socioeconómico nacional de duras aristas, repudiar este "mundo feliz" implicaba la inmediata expulsión de la "ciudadela modelo". Esto hizo que para muchos obreros la imposición paternalista fuera una realidad irrenunciable, donde no hubo ni opción, ni alternativa.

\section{REFERENCIAS}

Aracena, Francisco. La industria del cobre en las provincias de Atacama y Coquimbo. Santiago de Chile: Editorial Dirección de Bibliotecas Archivos y Museos Pontificia Universidad Católica de Chile, 2013.

Astorquiza, Octavio y Galleguillos, Oscar. Cien años del carbón de Lota, 18521952. Santiago de Chile: Editorial Compañía Carbonífera e Industrial de Lota, 1951.

Babiano, José. Paternalismo industrial y disciplina fabril en España (1938-1958). Madrid: Editorial Consejo Económico Social, 1998.

\footnotetext{
${ }^{32}$ Rocca, Enrique. "El Chile que vio un periodista italiano que viajaba en la nave Italia", El Sur, Concepción, 5 de octubre de 1924.
} 
Bustamante, Elisa. "El problema de la vivienda en la población obrera de la Compañía Carbonífera de Lirquén”. Tesis para optar al grado de Asistente Social. Concepción, Chile: Universidad de Concepción, 1942.

Cariola, Carmen y Sunkel, Osvaldo.Un siglo de historia económica de Chile, 18301930. Santiago de Chile: Editorial Universitaria, 1990.

Ciuffetti, Augusto. Casa e lavoro. Dal paternalismo aziendalealle "comunitáglobali": Villaggi e quartierioperai in Italia tra Otto en Novecento. Perugia: Editore Centre Ricerche Ambiente Cultura economía (CRACE), 2004.

Código Civil de la República de Chile. Santiago de Chile: Editorial Jurídica de Chile, 2011.

Cuevas, Fernando. "Ferrocarril, carbón y paternalismo industrial en Barruelo de Santullán”. Málaga: Actas IV Congreso de historia ferroviaria, 2006.

Endlicher, Wilfried."Desarrollo Histórico-genético y División Funcional del Centro Carbonífero", Revista de Geografía Norte Grande 13 (1986): 3-19.

Garcés, Eugenio. "Las ciudades del cobre. Del campamento de montaña al hotel minero como variaciones de la Company Town", Revista Eure XXIX/88 (2003): 321-358.

Garrido, Dionisio. "Habitaciones obreras de Lota", Sesión extraordinaria de la Cámara de Diputados, 15 de noviembre de 1939, Boletín de Sesiones, Santiago de Chile: Imprenta Nacional, 1939.

González, Sergio y Artaza, Pablo. "El concepto de «cantón salitrero» y su funcionalidad social, territorial y administrativa: Los casos de Zapiga, Lagunas y El Toco". En Sergio González. La sociedad del salitre. Protagonistas, migraciones, cultura urbana y espacios públicos, 1870-1940. Santiago de Chile: Editorial Ril - Universidad Arturo Prat, (2013): 325-363.

Hidalgo, Rodrigo. La vivienda social en Chile y la construcción del espacio urbano en el Santiago del siglo XX, Santiago de Chile: Editorial Centro de Investigaciones Diego Barros Arana, 2005.

Hurtado, Carlos. Concentración de la población y desarrollo económico: El caso chileno. Santiago de Chile: Editorial Universidad de Chile, 1966. 
Molina, Silvestre. "Condición económico-social de los mineros en la zona carbonífera”. Memoria para al grado de Licenciado en Ciencias jurídicas y Sociales. Chile, Santiago: Universidad de Chile, 1948.

Muñiz, Jorge. "La construcción social del espacio en el poblado minero metalúrgico de Arnao (Asturias), 1855-1937”, Scripta Nova. Revista Electrónica de Geografia y Ciencias Sociales, XI: 249 (2007). Disponible en: http://www. ub.es/geocrit/sn/sn-249.htm.

Muñiz, Jorge. Del pozo a Casa. Genealogías del paternalismo minero contemporáneo en Asturias. Asturias: Editorial Trea, 2008.

Noriel, Gérard. "Du "patronage" au "paternalisme": La restructuration des formes de domination de la main d'œuvre ouvrière dans l'industrie métallurgique française", Le Mouvement Social 144 (1988): 17-35.

Oficina del Trabajo. Las habitaciones obreras en Chile y en el extranjero. Santiago de Chile: Imprenta Santiago, 1911.

Porteous, J. Douglas. "Social Class in Atacama Company Towns", Annals of the Association of American Geographers 64/3 (1974): 409-417.

Scranton, Philip. "Variety of paternalism: Industrial structure and the social relations of production In American textiles", American Quarterly 36/2 (1984): 235-257.

Sierra, José. El Obrero Soñado: Ensayo Sobre el Paternalismo Industrial: Asturias, 1860-1917. Madrid: Editorial Siglo XXI, 1990.

Venegas, Hernán. "Paternalismo industrial y control social. Las experiencias disciplinadoras en la minería del carbón en Chile. Lota y Coronel, primera mitad del siglo XIX", Les cahiers ALHIM 12/27 (2014).

\section{Archivos y fuentes primarias}

\section{Archivos}

Archivo Fotográfico Biblioteca Nacional de Chile.

Archivo Histórico Nacional, Fondo Intendencia de Concepción, Vol. 1585 - 1976.

Archivo Nacional de la Administración, Fondo Ministerio de Salud, Vol. 277.

Archivo Empresa Nacional del Carbón, Prontuario 18 y 72. 


\section{Diarios y revistas}

El Alba, Coronel, 1902, 1903, 1904.

El Asalariado, Concepción, 1925.

Boletín de Sesiones de la Cámara de Diputados, Santiago, 1939.

La Defensa, Coronel, 1904, 1905, 1906.

Independiente, Coronel, 1933.

La Jornada, Schwager, 1920.

El Lota, Lota, 1877.

El Obrero, Coronel, 1943.

La Opinión, Lota Alto, 1924.

Oro Negro, Coronel, 1949.

La Prensa, Lota, 1897.

El Sur, Concepción, 1923, 1924.

La Trinchera, Coronel, 1939.

La Voz Obrera, Concepción, 1933. 